\title{
No heterophenomenology without autophenomenology: Variations on a theme of mine
}

\author{
Eduard Marbach
}

Published online: 15 November 2006

(C) Springer Science + Business Media B.V. 2006

\begin{abstract}
The paper assumes that the very source for an appropriate concept formation and categorization of the phenomena of consciousness is provided by prereflectively living through one's own experiences (of perceiving, remembering, imagining, picturing, judging, etc.) and reflecting upon them. It tries to argue that without reflective auto-phenomenological theorizing about such phenomena, there is no prospect for a scientific study of consciousness doing fully justice to the phenomena themselves. To substantiate the point, a detailed reflective and descriptive analysis of re-presentational experiences is presented, an essential property of which is their containing in themselves components that can only be individuated on the basis of reflection by the experiencing subject him- or herself. For heterophenomenology to account for them, autophenomenology is therefore presupposed.
\end{abstract}

Key words consciousness $\cdot$ heterophenomenology $\cdot$ mode of non-actuality phenomenology $\cdot$ reflective perspective $\cdot$ re-presentational experiences

If you want to avoid being taken, you will just have to think it through for yourselves (Dennett 1993, Caveat Emptor, p. 57).

In his recent paper, "Who's on first? Heterophenomenology explained," Daniel Dennett succinctly contends the following concerning the scope of heterophenomenology which he had been advertising as "an explicitly third-person approach to human consciousness" for already more than 20 years:

The total set of details of heterophenomenology, plus all the data we can gather about concurrent events in the brains of subjects and in the surrounding environment, comprise the total data set for a theory of human consciousness. It leaves out no objective phenomena and no subjective phenomena of consciousness (Dennett 2003, p. 20, emphasis mine).

With all the sympathy that I have with Dennett's long-standing attempt to devise ways of making the scientific study of consciousness, after decades of neglect in

E. Marbach $(\bowtie)$

Institute of Philosophy, University of Bern, Unitobler Laenggass-Strasse 49A,

CH-3009 Bern, Switzerland

e-mail: eduard.marbach@bluewin.ch 
many quarters, not only possible but even attractive for scientists (see Marbach, 1994), I disagree with him when he appears invariably to assert that a third-person methodology, by itself, is able to cover the ground - "all the ground" - of human consciousness (Dennett, 2003, p. 19). If you think it through, this cannot be true, and so heterophenomenology all by itself cannot work as the methodology for the scientific study of consciousness.

Ultimately, I think, Dennett's proposal cannot work for an amazingly simple reason: What consciousness in it itself consists in, as lived conscious experience of something of one kind or another, is nothing to be discovered in the objective world, period. To be sure, effects of consciousness, and causes of consciousness, neurobiological causes in particular, are to be found in the objective world and they are no doubt accessible to a heterophenomenological methodology, directly or indirectly. And so is all the observable behaviour (gestures, expressions, actions, speech-acts, etc.) of all kinds of creatures out there. But I have a hard time understanding that apparently not everyone interested in the study of consciousness agrees to the following view: That no one would ever think of anything like conscious experiences and develop any concepts concerning them, let alone concepts open to scientific validation, intersubjective confirmation or falsification, who did not experience them as such in the first place, i.e., originally as his or her own experiences, thereby being provided with the very source for an appropriate concept formation and categorization of the phenomena of consciousness. No one, that is, who is not him- or herself a conscious experiencer of something or other, a creature that senses, perceives, imagines, remembers this or that, etc., would ever be able to detect or to identify conscious experiences, i.e., the very explananda of a science of consciousness, by observing some behaviour or other simply "from the outside."

For phenomena of consciousness are first of all a matter of acquaintance by being experienced or lived through in the many ways of being pre-reflectively active, doing something or reacting to something. Only derivatively, by way of representing them as someone else's phenomena, discernible on the basis of various ways of behaving, do conscious experiences at all get somehow objectified, attributed to other creatures out there.

Now, am I not forcing an open door? After all, Dennett himself appears to be readily prepared to concede at the outset of his paper that "on the face of it, the study of human consciousness involves phenomena that seem to occupy something rather like another dimension: the private, subjective, 'first-person' dimension," and to generalize on top of it: "Everybody agrees that this is where we start." Moreover, he notes that "with the best of intentions" people working on consciousness, bedevilled by a pattern of miscommunication, "are talking past each other" (Dennett, 2003, p. 19). Well, expressions such as 'on the face of it,' 'seem to occupy' and, especially, 'where we start' should come as a warning to anyone inclined to think that Dennett himself is holding a view that gives the subjective, first-person perspective an essential role throughout the study of consciousness, and not merely one of getting the properly scientific investigations going with the help of the explicitly "third-person methodology, dubbed heterophenomenology" (Dennett, 2003).

Ever since I encountered Dennett's idea of heterophenomenology, I sensed an affinity to theoretical concerns of mine that had been inspired by Husserl's project of applying "pure" or a priori, eidetic phenomenology to empirical, scientific studies of 
consciousness. Husserl conceived of this project as interpretation of data from the point of view of pure phenomenology, and he labelled it "empirical" or "applied phenomenology," in analogy to the application of "pure" or a priori mathematics to physics (see Marbach, 1988). As regards Dennett's project of heterophenomenology, however, it is my conviction that the very idea of wanting to attribute to a creature out there anything like a heterophenomenological world - a world according to that creature, its subjective world (Dennett, 2003, p. 20), "populated with all the images, events, sounds, smells, hunches, presentiments, and feelings that the subject (apparently) sincerely believes to exist in his or her (or its) stream of consciousness" (Dennett, 1991, p. 98) - can only be made intelligible if the objective, third-person perspective that Dennett proposes to adopt is itself submitted to methodical clarification in relation to a reflection-based phenomenology of conscious experience in it itself (Marbach, 1994).

In the course of the present paper, therefore, I will argue for deliberately integrating, and not displacing, the reflective perspective on phenomena of consciousness offered by autophenomenology with the third-person perspective of heterophenomenology, "phenomenology of another not oneself" (Dennett, 2003, p. 19). ${ }^{1}$ I will try to show in some detail how the reflective phenomenological findings concerning conscious experiences really are material of a different kind from what a Dennettian heterophenomenologist dealing with consciousness is able to uncover, and, as a result, that the heterophenomenological method is in need of a substantive enlargement or revision. ${ }^{2}$ Accordingly, Dennett's Gell-Mannesque question, "Why not live by the heterophenomenological rules?" will here get a data-driven answer, not

\footnotetext{
${ }^{1}$ In arguing along such an integrative line, I feel in good company. See, e.g., Thompson, Noë, \& Pessoa (1999), who conclude their case study in phenomenology and cognitive science, throughout which they give particular attention to Dennett (1991), with the observation that "Dennett's exclusively third-person approach to experience becomes unacceptable" (p. 195). These authors, too, clearly argue in favour of integrating third-person and first-person data: "it is possible to pursue the descriptive, conceptual, and phenomenological study of personal-level experience in tandem with psychophysical and cognitive neuroscientific research," also pointing out that unless our lived perceptual experience has been "conceptually clarified and systematically described, our scientific explanations will always be incomplete" (p. 195). Compare also Chalmers (1999, 2004) for an explicit endorsement of integrating third-person and first-person data in the construction of a science of consciousness. See also Gallagher (2003), which contains a critical discussion of Dennett's heterophenomenology akin to my own. In Marbach (2005), the case for integrating the two classes of data concerning consciousness is further pursued.

${ }^{2}$ I therefore try to take up the challenge Dennett many years ago put to me in a constructive critical reading of an expanded draft of the paper that I had presented at the 16th International Wittgenstein Symposium in August 1993 (see Marbach, 1994, p. 263, note 17). In that paper I discussed in some detail Dennett's (1991) own example of imagining a purple cow in contrast to imagining a yellow cow, as well as Dennett's example of remembering an episode of sitting in a rocking-chair. There, I had tried to point out that the crucial differences of the examples were all to be found in the very structures of representational consciousness of one kind or another that Husserlian phenomenology permitted to describe in detail. Dennett, in private correspondence, generously acknowledged that my proposals offered "valuable" details, making "for a more sophisticated and nuanced and realistic phenomenology," but he also said "in any case, 'just' a lot more grist from my heterophenomenological mill - more data," and he added that he didn't "see it as valuable material of a different kind from the rest," that he could "accept almost all your phenomenological fruits without having to adjust my phenomenological method very much - just going in for your sorts of important further details." That was back in January 1994.
} 
an ideology-driven one, as he would like to impute to those who are reluctant to acquiesce in heterophenomenology as one's method in the study of consciousness. Boldly, then, I want to set out to challenge Dennett's (2003, p. 29, emphasis mine) adamant statement to the effect that "Nobody has yet pointed to any variety of data that are inaccessible to heterophenomenology." If I succeed, Dan Dennett should, after all, be prepared to say 'yes, now that you have brought me to think it through by myself, I see what you mean, and I suspect you're right,' and he should welcome the prospect of a substantive enlargement and revision of his own methodology by integrating the novel data from the reflective phenomenological perspective, allowing thereby an indispensable role for reflective autophenomenology in the very theory formation about consciousness.

To be sure, in trying to convince someone like Dennett who adopts "naturalism" as "the default position" of his project, ${ }^{3}$ it is no doubt to be recommended to align myself with all those who are doing "justice to all the data without ever having to abandon the rules and constraints of the experimental method that have worked so well in the rest of science" (Dennett, 2003). So, I myself believe results of the modern sciences to the effect that over thousands and thousands of generations evolution by natural selection has produced an adapted universal human psychological architecture with a complex multitude of mechanisms. But on the basis of the best of our current scientific knowledge I also keep believing that "something" has been selected in virtue of the development of nervous systems that can originally be experienced as what it is and what it is like solely from the experiential perspective of experiencing creatures themselves - namely, conscious experience. And it is here that the first-person or autophenomenological, experiential as well as reflective, attitude or stance fully comes to its own. It provides the very basis for building a theory that uses properly phenomenological concepts concerning the phenomena of consciousness and is to be integrated with the theoretical framework constructed by the third-person approaches to consciousness. Based on the reflective phenomenological attitude, my theoretical interest has for many years been captivated by the scientific evidence that, phylogenetically and ontogenetically, conscious experience of lower and higher complexity is to be found. Interpreting the evidence in phenomenological terms, I think in particular of the difference between, on the one hand, conscious experience that is constitutive for a creature's being in contact with what is presently given here and now, in sensation and perception, and, on the other hand, conscious experience that is constitutive for someone's being intentionally referring to something in its absence (in the past, in the future, elsewhere in time and space than here and now, in purely fictional worlds, in depicted or otherwise signified worlds, in a heterophenomenological world of another, etc.), by means of re-presentational experiences of one kind or another.

In general, then, I very much agree with Dennett (1991, p. 22), that "the phenomena of consciousness... do not need to be protected from science." However, in order "to save the rich phenomenology of consciousness for scientific study"

\footnotetext{
${ }^{3}$ See Dennett's exchange of letters with David Carr in Dennett and Carr (1994, p. 15).

를 Springer
} 
(Dennett, 1993, p. 50), his exclusive focus on the indirect third-person access of heterophenomenology to the beliefs of subjects about their experiences must be combined with studying the experiences themselves from the original, pre-reflective and reflective perspective of (auto)phenomenology. There simply is no prospect of an illuminating study of conscious experience from an exclusively third-person approach, whether pre-scientifically or scientifically. Nor will metaphors of consciousness do. What insight is there to be gained regarding what it is like to be conscious of something in one way or another, if you are told that consciousness is, or is not, rather something like "the Cartesian Theater," "the Central Meaner," "virtual machines," "a Pandemonium of Homunculi," "a species of mental fame" or "fame in the brain," etc.? None, I suspect. ${ }^{4}$ Instead, the experiential perspective as such must be taken into account, and it can profitably be taken up along the lines of a Husserlian reflective phenomenology of conscious experience in itself. Perhaps, one of the most difficult aspects of wanting to construct a science of consciousness is linked, precisely, to the need of leaving behind all kinds of indirect, metaphorical or analogical characterizations of conscious experiences and to stick, instead, soberly to describing the reflective data themselves in the first place, elaborating thereby genuinely phenomenological concepts that allow us to classify phenomena of consciousness according to structures or forms of one kind or another. This seems to me the only way of positively saying something about consciousness purely in itself ("Bewusstsein rein als es selbst," as Husserl liked to put it) - without wallowing in mystery, something Dennett rightly chastises.

Let me now turn to a class of examples and try to argue my case for material of a different kind from what a heterophenomenologist is able to offer concerning conscious experiences, material that in my view is owing to reflectively clarified knowledge about conscious experiences, and only to such knowledge. For the sake of making my point more readily obvious, it helps to take examples of conscious experience of a certain complexity. I want you to consider a property that, upon analysis, you would be willing to count as belonging to the various species of conscious experiences of a certain kind, and of which it is true that it can only be made intelligible as a property of conscious experience from the reflective perspective of an autophenomenological analysis. If we then want to establish a scientific theory of consciousness - of conscious experiences - this property, too, should be explained or accounted for scientifically, i.e., from a third-person perspective; ex hypothesi, though, it is a property reported by the phenomenologist to be such that it is only to be made intelligible as belonging to the conscious experience in question to someone who him- or herself adopts the reflective perspective, and thus it at least looks to be inaccessible to heterophenomenology. Before discussing what Dennett no doubt would object at this point, let me first describe the examples that I have in mind in greater detail. It is indeed important for the impact of my argument to get a somewhat lively feeling of what I am talking about, and so details are de rigueur.

\footnotetext{
${ }^{4}$ See also, e.g., Bennett and Hacker (2003) for reservations regarding Dennett's use of metaphors of consciousness (p. 432, in particular).
} 
From a phenomenological reflective perspective, I take it as a datum that with acts of mental re-presentations - such as remembering, imagining, viewing something in a picture and any combination thereof - we have to do with certain unified structures of actually occurring conscious experiences, an essential property of which is to be containing in themselves components that, from the experiential point of view, function in the mode of non-actuality, thereby transcending the temporally present experience of re-presenting something in one way or another. From a heterophenomenological perspective, on the other hand, I assume, everything physically necessary and together sufficient for bringing either this or that conscious experience presently about, such that I am able to report to be experiencing it, does occur in the brain at present. For example, when I am engaged in an activity of visually representing, thereby actually intentionally referring to something - say, a past event that I remember visually, or a possible one that I imagine, or an object, say Dennett's (1991) cow, that I see as being depicted in a picture - then not only is the re-presented object or event consciously given to me as being not actually present, but at the same time the conscious experience of so referring to something absent contains within its very structure an experiential component of not actually performed perceiving (seeing). If so, then there is something actually occurring in my conscious life an essential property of which is that parts of it are consciously experienced as non-actual; and I do not understand how an observer adopting an exclusively heterophenomenological approach to what I would report would be able even to understand the very meaning of what I am talking about, reporting, or describing, let alone be able to judge the truth-value of what I am reporting.

So let me expand on some of these structures of conscious experiences with a more refined analysis along Husserlian lines. The case of viewing pictures is, perhaps, particularly well suited to start a more detailed phenomenological report of what differently structured conscious experiences are able to achieve. ${ }^{5}$ The phenomenologist's claim is, indeed, that for an object to have the character of a picture, i.e., to be a pictorial representation, is nothing intrinsic to this object but is so only for an appropriately structured conscious experience constituting the picture as a representation. In view of my main argument, it is instructive to compare what it is for an object to be a pictorial object appearing, say, in a variation of the color yellow, with what it is for an object out there in the real world to be appearing yellow, or any other color. I would argue that as much as the phenomenal quality 'yellow' that I, for example, attribute to the cow over there in the meadow depends for its appearing - like any other phenomenal quality - on my perceptual apparatus in ways that science elaborates in detail, it is not the case that the real cow's appearing to be yellow is appearing so only because of my taking it as appearing

\footnotetext{
${ }^{5}$ In Marbach (1994), I had not discussed the case of "painted pictures of cows on canvas" that Dennett (1991) had mentioned in passing, among others, as being different from cows that "are just imagined cows," i.e., the case that I had discussed in detail. Presently, I turn to the case of pictures and hope better to succeed in describing the property of "non-actuality" that I judge to be particularly well-suited for illuminating my main argumentative point against Dennett's exclusive third-person approach to a science of consciousness.
} 
yellow in virtue of an appropriately structured conscious experience. Rather, the manifest presence of the sensory or phenomenal quality 'yellow' in a corresponding visual experience is a given, a datum, in my waking life. ${ }^{6}$ Considered in isolation as the phenomenal quality 'yellow' that is exemplified in my visual experience, there is even no difference between seeing something yellow out there in the real world and seeing something yellow in a pictorial representation.

But now consider a change from a conscious experience of simply perceiving the yellow cow over there in the meadow to a conscious experience of pictorially representing a yellow cow and its surroundings. Here, reflective analysis is able to articulate a radical difference regarding the structure of the corresponding conscious experiences themselves and, correlatively, of the ways of givenness of the yellow cow and its surroundings. To begin with, notice the following aspect. Concretely viewed this time, i.e., not in isolation, the color yellow in the pictorial representation is attributed, not to a portion of the flat canvas as such that I actually see over there, but rather either to the merely pictorially appearing but not actually given cow "on" the canvas or to the depicted and again not actually given cow somewhere in the real world or in a fictional space, depending on where the person viewing the picture is focusing her attention. Either way, the presently manifest quality yellow is here taken, or apprehended, as a property of an object that is not actually present over there where the canvas actually is and where the phenomenal quality yellow appears. If so - namely in so far as I have conscious experience of the yellow as of a property of the cow - the phenomenal quality yellow cannot be given solely in virtue of a sensory-perceptual visual experience; for there is actually no cow to be visually perceived over there on the wall where the painting is hanging. What we have instead is a more complex conscious experience of intentionally referring to the depicted cow by way of seeing as it were the yellow cow in so far as it appears on a canvas, i.e., as a pictorial object. In its unified structure such an experience also involves as a conscious component among others my seeing the yellow cow in the mode of non-actuality, namely precisely in so far as the cow appears on the canvas over there that I actually see. In this case, then, the phenomenal quality yellow appears no longer as actually belonging to a portion of the canvas or the picturesurface over there. But the pictorially appearing cow's being yellow - in contradistinction to the perceptually appearing cow's being yellow - only appears so because of my consciously taking the pictorial object 'cow' to be a representation of an absent (real or imaginary) animal that is only depicted in the picture that I actually see in the present surroundings.

Crucially, the conscious component of my seeing in the mode of non-actuality can be said to be intentionally implied in the unified conscious experience that I have of seeing something pictorially represented, and clearly this is not a matter of being spatially contained within the experience. Let me spell this out in a little more detail since precisely such findings concerning the structure of one's experiences seem to me to be discoverable from the reflective perspective only. What other components are there in such a unified experience of pictorially representing something that do

\footnotetext{
${ }^{6}$ See Lanz (1996) who points out that this is so, independently of the question whether the experience is part of veridical or non-veridical perceptions.
} 
not stand in spatial relations to one another and can therefore only reflectively be distinguished as such? Consider first that while I am intentionally referring to the yellow cow by way of only re-presenting to be seeing, not actually seeing, the cow in so far as it appears in the picture over there, I am simultaneously aware of my present surroundings here and now in virtue of actually perceiving the world around me as well, although somewhat less attentively as long as I am interested in the depicted scene or in the scene as it pictorially appears on the canvas. The fact that I take the cow and its surroundings not to be actually present over there depends, precisely, on a consciously experienced contrast concerning the ways of givenness of the objects around me, and among them the picture on the wall showing the yellow cow in its surroundings, on the one hand and, on the other, the ways of givenness of the cow either in so far as it pictorially appears on the canvas or is taken as the depicted cow somewhere in the world, respectively. There is a clash between that which I take to be actually real around me and that which I take to be just a pictorially represented, not actually given scene. It is in relation to this pictorially appearing or depicted scene in contrast to the actually perceived surroundings that I speak of seeing something in the mode of non-actuality; for I cannot actually see what is not actually there. To be sure, I actually look over there to the picture and thus, in a sense, I actually see something over there, just as I actually see the wall over there where the whole picture that I actually see is hanging - I actually see patches of yellow etc. However, as I want to urge, as soon as I take those yellow patches to be ways of appearing of a cow - be it the cow in so far as it appears in the picture or the depicted real or imaginary cow - the very experience of seeing is consciously modified: I do not believe actually to see a cow over there. To the extent that in picture viewing vision is involved in relation to the pictorially appearing objects, it is altogether experientially modified, not unlike what obtains in visually remembering or imagining something that is not actually, presently given - and yet, not quite like it either.

To clarify matters further, notice next that with my seeing as it were the yellow cow in its surroundings in so far as it appears in the picture or is depicted by the picture that I actually see over there, I do not simply intentionally refer to the cow as if I were seeing the cow itself in some imaginary or remembered place. Yet, there is similarity to some extent between picture viewing and imagining or remembering, namely to the extent, precisely, of involving a visual experience in the mode of nonactuality and an object that is not actually given. For notice that in the case of, say, an experience of simply imagining a cow in an imaginary surroundings, the cow would again not actually be given but appear as it were, this time in relation to an imaginarily occupied point of view of mine from where I would see the animal itself, if only as it were, i.e., in a consciously modified manner. This is to say that once again vision would not be functioning in a standard way. My visual experience would indeed not actually be performed but only represented: it would be as if I were seeing the not actually given cow from some place, at some distance and orientation relative to my standpoint in the imaginary space. By contrast, when I intentionally refer to the cow in so far as it appears in the picture, I can do so only because at the very same time I am aware of the cow's merely being a pictorial representation of a animal, be it a real animal in the world or be it merely a fictional 
animal. The situation, in picture viewing, is indeed rather special, as has often been observed. ${ }^{7}$ I am neither simply actually perceiving or seeing an object "in" a picture, nor am I simply purely mentally representing the not actually given object itself, say, in remembering or imagining it in a different space and a different time. Rather, to sum up, in picture viewing, i.e., when I pictorially represent some absent object - a thing, person, animal, place, or event - I am intentionally referring to the absent, not actually given object (the so-called sujet, say, of a painting) by means of my representing a non-actual perceiving of the object (the sujet) in so far as it appears in the actually perceived picture while simultaneously presenting my actual surroundings here and now.

In such conscious experiences of purely mentally or of pictorially re-presenting something absent (as past, future, merely possible, or elsewhere in space, etc.), as well as in even more complex conscious experiences of mentally re-presenting something absent by way of re-presenting an act of pictorially re-presenting it (say, in remembering or imagining an episode of picture viewing), there is always the reflective phenomenological finding of those components of non-actuality belonging to the very structure of the actually experienced mental activity: one's being conscious or aware of intending something absent, and one's being conscious or aware of the non-actual experience - in the simplest case, a perceptual experience that is implied in the actually occurring establishment of the intentional reference to the absent object. Notice that the simultaneously experienced presentation of one's actual surroundings could occur independently of my re-presenting something beyond the present. By contrast, the very givenness of the intended absent, not actually given object as well as the very givenness of the intentionally implied nonactual component of, say, seeing as it were the absent object, is bound to occur within the unified structure of the actually performed conscious experience of representing together with the presentation of the actual surroundings. In this sense, then, I think that, with each instance of an actually occurring conscious experience of re-presenting something absent in virtue of components that are experienced as non-actual, we have clear examples of actually existing entities in our world that do not fit into the framework of an exclusively third-person, heterophenomenological

\footnotetext{
${ }^{7}$ See, e.g., Gregory (1970): "Pictures have a double reality... Pictures are unique among objects; for they are seen both as themselves and as some other thing, entirely different from the paper or canvas of the picture. Pictures are paradoxes. No object can be in two places at the same time; no object can lie in both two- and three-dimensional space. Yet pictures are both visibly flat and three-dimensional. They are a certain size, yet also the size of a face or a house or a ship. Pictures are impossible. No eyes before man's were confronted by pictures. Previously, all objects in themselves were important or could be safely ignored. But pictures, though trivial in themselves, mere patterns of marks, are important in showing absent things. Biologically this is most odd." (p. 32; emphasis in the text). Also compare Gregory (1974): "Pictures are most odd. They have, perceptually, a kind of double reality: they exist as objects in their own right - and at the same time they represent quite other objects, in a different space and a different time.... This double reality is common to all symbols, and it presents a problem that only the human brain can solve.... Pictures are paradoxical, impossible, and yet by accepting them we became unique in nature." (p. 617; emphasis partly mine). Also see Gibson (1980): “The perception of surfaces, I argue, is radically different from the perception of markings on a surface... Surfaces and what they afford are actually perceived. Pictured surfaces, objects, places, persons, and events are not actually perceived in the proper meaning of that term.... Perplexities... If so, we should not speak of the perception of a picture but of a nonperceptual kind of apprehension... the human observer gets a puzzling variety of new experiences" (p. xi ff.).
} 
approach to consciousness. At any rate, those non-actual components of the actually occurring experiences of re-presenting something seem to me to make up an essential property of these experiences that can only be individuated on the basis of reflection by the experiencing subject him- or herself as being a consciously modified re-presented part of the subject's actual experience of re-presenting something.

Now, Dennett of course regards first-person data for a science of consciousness with deep suspicion. As he puts it in, e.g., Dennett (2001a): "There is no such thing as first-person science, so if you want to have a science of consciousness, it will have to be a third-person science of consciousness...." Elsewhere he claims that his third-person heterophenomenological methodology is "the sound way to take the first person point of view as seriously as it can be taken" (Dennett, 2003, p. 19), and this amounts to "bringing the data of the first person into the field of objective science" (Dennett, 2001b, p. 3). According to Dennett, it has, on the one hand, "always been good practice for scientists to put themselves in their own experimental apparatus as informal subjects, to confirm their hunches about what it feels like, and to check for any overlooked or underestimated features of the circumstances that could interfere with their interpretations of their experiments." But on the other hand, he continues, "scientists have always recognized the need to confirm the insights they have gained from introspection by conducting properly controlled experiments with naive subjects." As long as this obligation is met, Dennett adds, "whatever insights one may garner from 'first-person' investigations fall happily into place in 'third-person' heterophenomenology" (Dennett, 2003, p. 23). Roughly, then, the way for the heterophenomenological investigator to proceed is "to compose a catalogue of what the subject believes to be true about his or her conscious experience" (Dennett, 2003, p. 20), adding "all the other manifestations of belief, conviction, expectation, fear, loathing, disgust, etc., including any and all internal conditions (e.g., brain activities, hormonal diffusion, heart rate changes, etc.) detectable by objective means" (Dennett, 2001b, p. 2). Similar statements from Dennett's writings could be multiplied.

Probably, then, Dennett would object to the kind of reflection-based results that I have just presented along the following lines. He may say to me (I change the pronouns in the quote to fit the addressee): If you as a phenomenologist become "convinced by your own (first-)personal experience, however encountered, transformed, reflected upon, of the existence of a feature of consciousness in need of explanation and accommodation within your theory, your conviction that this is so is itself a fine datum in need of explanation, by yourself or by others, but the truth of your conviction must not be presupposed by science" (Dennett 2001a, p. 230; see also Dennett 2003, p. 23). Yes, precisely - all along I have insisted on that peculiar property or feature of consciousness that I described as experiencing in the mode of non-actuality belonging to the very structure of an actually experienced mental activity of re-presenting something. Of such a reflective finding of how it is with me when I re-present something absent, I am indeed convinced. And if my conviction that this is so - that there is such a feature of consciousness - is itself a fine datum in need of explanation, I don't object. I also agree with Dennett that "the truth" of my conviction "must not be presupposed by science."

But I must now explicitly draw attention to a crucial point in this whole discussion. The data concerning conscious experiences of re-presenting something 
that I pointed out in some detail with the help of reflective phenomenology applied to the case of viewing a picture are not simply owed to naive everyday introspection. In everyday life we live through various experiences and in so doing we are normally, I think really most of the time, interested in the object (thing, person, event etc.) and its properties and relations to other objects (things, persons, events, etc.) out there in the world to which we are consciously related. To be sure, we also occasionally introspect our conscious life, we have hunches, premonitions etc. etc., in short a "private, subjective, 'first-person' dimension" (Dennett, 2003, p. 19) to which we can turn our attention, inwardly so to speak, and for whatever motive. Now, when consciousness shall become the subject-matter for a theoretical investigation, a philosophical or a scientific one, I, too, can in a sense agree when Dennett says, "everybody agrees that this is where we start" (Dennett, 2003, emphasis mine). In daily life, we are pre-reflectively aware of the conscious experiences that we live through, we are acquainted with our conscious life, we know about it implicitly. Without having to introspect myself or to reflect upon what I am presently doing, there is something it is like to imagine some object or event that differs from what it is like to remember something or to view something in a picture, etc. Clearly, everyday languages with their mental vocabulary reflect just this: that people are living a more or less differentiated conscious life and have folkpsychological or common concepts of their conscious mental life that find their linguistic expression. Theoreticians, too, must start from this linguistic common ground concerning our conscious life. But then, things start to become quite difficult.

Philosophers such as James, the great introspectionist of our mental life, ${ }^{8}$ and Husserl, an admirer of James' Principles of Psychology (1890), similarly pointed out how misleading everyday language can be when it comes to describe conscious mental life or phenomenological matters. As James has it: "Language was originally made by men who were not psychologists and most men today employ almost exclusively the vocabulary of outward things... This absence of a special vocabulary for subjective facts hinders the study of all but the very coarsest of them." And to continue a little later, that "the lack of a word" often makes us "prone to suppose that no entity can be there; and so we come to overlook phenomena whose existence would be patent to us all, had we only grown up to hear it familiarly recognized in speech. It is hard to focus our attention on the nameless, and so there results a certain vacuousness in the descriptive parts of most psychologists" (James 1983, p. 193f., see also p. 230). Husserl in turn points out that "where the phenomenological interest is decisive, we labour at the difficulty that we are to describe phenomenological matters that we have experienced innumerable times, but that normally are not conscious objectively, and that we have to describe them with expressions that are tuned to the sphere of the normal interest, to the appearing objects."9

To be sure, I am not suggesting that participants in experiments that are concerned with establishing a scientific theory of consciousness should themselves

\footnotetext{
${ }^{8}$ Regarding the appreciation of James' introspection-based contribution to psychology, I sharply disagree with Bennett and Hacker when they find it "disturbing" that eminent cognitive neuroscientists such as Baars and Edelman think very highly of James! (Bennett \& Hacker, 2003, p. 327, note 10).

${ }^{9}$ See Husserl (1984), I. Ausdruck und Bedeutung, 10:48.
} 
be sophisticated (Husserlian) phenomenologists or (Jamesian) introspective psychologists. It is fine if participants are just "naive subjects" in properly controlled experiments. But I want to urge that it is not fine, if the scientists, too, are naive as far as consciousness is concerned, simply drawing on their introspection and their hunches about what it feels like. If consciousness is to become the subject-matter of a scientific investigation, it is no less mandatory - if scientific standards are to be maintained, and there is no reason (I fully agree with Dennett on this) why they shouldn't in the case of consciousness studies - that the best available knowledge of consciousness itself, of conscious experiences themselves, and not just more or rather less enlightened beliefs of naive participants be relied upon. Such knowledge, however, as it is required for the formation of properly phenomenological concepts that do justice to the intricacies of, e.g., conscious experiences of re-presenting something, of which I have presented some elements above, cannot be had from the objective third-person perspective. It must be acquired through reflection by each and everyone upon the structures of his or her conscious experiences. Expressions such as "seeing in the mode of non-actuality" that the phenomenologist may produce in his speech-acts or sentences in an effort of describing that essential feature of certain kinds of consciousness can only be understood from the reflective perspective itself, i.e., from the point of view of an autophenomenologist. In other words, the understanding of the very meaning of phenomenological terms depends on one's adoption of a first-person reflective attitude; only from this standpoint can the referents of the terms and the states of affairs corresponding to the descriptions become intelligible. And only then - when each one interested in establishing the truth or falsity of such phenomenological claims does adopt the reflective attitude upon a re-presented instance of the conscious experience in question - will we have a basis for deciding about the truth-values of the (auto-) phenomenological statements: by way of communicating from subject to subject, and in this sense intersubjectively. Once again, the main reason for this peculiar situation is that consciousness in itself is not to be found and identified in the objective world.

Let me conclude my plea in favour of explicitly integrating the first-person or reflective perspective of autophenomenology into a science of consciousness with the following thought. I am very much tempted to say that just as regarding the workings of the brain, before the advent of modern neuroscience, people in their ignorance had fanciful ideas, images, metaphors (e.g., the heating system of the Roman baths as model for the ventrical system; processes of purification throughout the ventricles modelled after the repeated distillation of the spirits of wine, etc.) about the brain for thousands of years (see Clarke \& Dewhurst 1996), just so, inappropriate images and metaphors about consciousness still abound in everyday contexts and also in the cognitive sciences, although with the advent of properly conducted reflective phenomenology of the conscious life this, too, should gradually change and give way to more adequate descriptions of the very phenomena of consciousness themselves.

Finally, my theme again: If you want a science of consciousness, go also to the finer details on the side of the conscious experiences themselves, with the help of reflective phenomenology, and combine this reflection based knowledge with neuroscientific knowledge of the details in the brain, where "the recent history of neuroscience can be seen as a series of triumphs for the lovers of detail. ... Many of 
the fond hopes of opportunistic minimalists have been dashed: they had hoped they could leave out various things, and they have learned that no, if you leave out x, or $y$, or z, you can't explain how the mind works" (Dennett, 2001a, p. 234). Clearly, then, "the total data set for a theory of human consciousness" (see above) must include autophenomenological first-person data; they certainly are part of "the organization of the data, ... of what must be explained" (Dennett, 2003, p. 27, emphasis in the text): no heterophenomenology without autophenomenology.

Acknowledgments I wish to thank an anonymous referee for helpful suggestions and Gianfranco Soldati for a most instructive discussion of some of the points in the present paper.

\section{References}

Bennett, M. R., Hacker, P. M. S. (2003). Philosophical foundations of neuroscience. Oxford, UK: Blackwell.

Chalmers, D. (1999). First-person methods in the science of consciousness. Consciousness Bulletin. Consciousness Studies. Department of Psychology, The University of Arizona, Tucson, 8-11.

Chalmers, D. (2004). How can we construct a science of consciousness? In M. Gazzaniga (Ed.), The cognitive neurosciences III. Cambridge, Massachusetts: MIT (section X, chapter 79).

Clarke, E., \& Dewhurst, K. (1996). An illustrated history of brain function. Imaging the brain from antiquity to the present. San Francisco: Norman (2nd ed., revised and enlarged).

Dennett, D.C. (1991). Consciousness explained. Boston: Little Brown.

Dennett, D. C. (1993). Caveat emptor. Consciousness and Cognition, 2, 48-57.

Dennett, D. C. (2001a). Are we explaining consciousness yet? In Dehaene (Ed.), The cognitive neuroscience of consciousness (pp. 221-237). Cambridge, Massachusetts: MIT.

Dennett, D. C. (2001b). The fantasy of first-person science. Third draft. March 1, http://ase.tufts.edu/ cogstud/pubpage.htm, (pp. 1-11).

Dennett, D. C. (2003). Who's on first? Heterophenomenology explained. Journal of Consciousness Studies, 10(9-10), 19-30.

Dennett, D. C., \& Carr, D. (1994). Dennett and Carr further explained: an exchange. Emory Cognition Project Report \#28, Department of Psychology, Emory University Atlanta, Georgia 30322.

Gallagher, S. (2003). Phenomenology and experimental design. Toward a phenomenologically enlightened experimental science. Journal of Consciousness Studies, 10(9-10), 85-99.

Gibson, J. J. (1980) Foreword: A prefatory essay on the perception of surfaces versus the perception of markings on a surface. In M. A. Hagen (Ed.), The perception of pictures, (vol. 1). Academic, New York, ppxi-xviii.

Gregory, R. L. (1970). The intelligent eye. London: Weidenfels and Nicolson.

Gregory, R. L. (1974). Concepts and mechanisms of perception. New York: Scribner.

Husserl, E. (1984). Logische Untersuchungen. Zweiter Band, Erster Teil. Untersuchungen zur Phänomenologie und Theorie der Erkenntnis. Husserliana XIX/1, In U. Panzer (Ed.), The Hague: Martinus Nijhoff (originally published in 1901).

James, W. (1983). The principles of psychology (originally published in 1890). Cambridge, Massachusetts: Harvard University Press.

Lanz, P. (1996). Das phänomenale Bewusstsein. Eine Verteidigung. Frankfurt: Klostermann.

Marbach, E. (1988). How to study consciousness phenomenologically, or quite a lot comes to mind. Journal of the British Society for Phenomenology, 19, 252-268.

Marbach, E. (1994). Troubles with heterophenomenology. In R. Casati, B. Smith, \& G. White (Eds.), Philosophy and the cognitive sciences. Proceedings of the 16th International Wittgenstein symposium, 15-22 August 1993, Kirchberg am Wechsel. Vienna, Hölder-Pichler-Tempsky, 247-264.

Marbach, E. (2005) On bringing consciousness into the house of science - with the help of Husserlian phenomenology. Angelaki, Journal of the Theoretical Humanities, 10(1), 145-162.

Thompson, E., Noë, A., \& Pessoa, L. (1999). Perceptual completion: A case study in phenomenology and cognitive science. In Petitot et al. (Ed.), Naturalizing phenomenology. Issues in contemporary phenomenology and cognitive science (pp. 161-195). Stanford: Stanford University Press. 